Military Technical College Kobry El-Kobbah, Cairo, Egypt

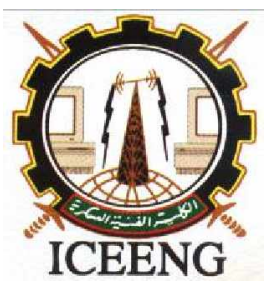

\author{
$6^{\text {th }}$ International Conference \\ on Electrical Engineering \\ ICEENG 2008
}

\title{
6.5 kV IGBT switch realization possibilities and their feasibility study for high-power applications
}

By
D. Vinnikov ${ }^{*}$
J. Laugis*
R. Strzelecki ${ }^{* *}$
M. Egorov*

\section{Abstract:}

In recent years, the demand for the high-voltage (HV) conversion applications such as high-voltage inverters, high-voltage pulse generators, high-voltage DC transmission lines, flexible AC transmission systems, high-voltage DC traction, etc., have been increased. This requires primary inverter switches with the high-voltage blocking capability to be implemented. The latest trend in high-voltage high-power electronics is connected to the implementation of single high-voltage IGBT modules. These devices (produced by Infineon, ABB, IXYS, DYNEX, etc.) are basically designed for the HV applications with the nominal DC-link voltage of $3.6 \mathrm{kV}$. Single HV IGBT gives an attractive possibility to avoid series connection of transistors thus achieving better efficiency, power density and reliability compared to the combined HV switch designs. But the single HV IGBT is relatively slow in operation as compared to series-connected IGBTs with the lower voltage blocking capability. Thus, the opportunity of using each of the above HV IGBT switch solutions (i.e., series-connected IGBT or single HV IGBT) into the different applications should make factors related to the circuit complexity, cost, efficiency, dimensions, and reliability of the designed system. This paper presents the feasibility study of the different IGBT switch solutions for the $6.5 \mathrm{kV} / 200 \mathrm{~A}$ application.

\section{Keywords:}

DC to DC converters; modeling, analysis and application; rolling stock applications; inverters; distributed generation and renewable energy systems; optimal design

\footnotetext{
* Tallinn University of Technology, Tallinn, Estonia

** Gdynia Maritime Academy, Gdynia, Poland
} 


\section{Introduction:}

Up to today, the high-voltage blocking capability requirement in IGBT converters was successfully fulfilled by the series connection of IGBTs with the lower voltage ratings [1-7]. In that case, the total input voltage blocking capability of the inverter is equal to the sum of the blocking capabilities of series connected IGBTs:

$$
\mathrm{U}_{\text {b.c., } \Sigma}=\mathrm{U}_{\text {b.c., IGBT }} \times \mathrm{n} \text {, }
$$

where $\mathrm{U}_{\text {b.c.,IGBT }}$ is the input voltage blocking capability of a single IGBT and $\mathrm{n}$ is the number of series connected transistors. The second item to be taken into account is the nominal value of the converter DC-link voltage $\left(\mathrm{U}_{\mathrm{DC}}\right)$. Thus, the number of IGBTs selected for the series connection must be coordinated to keep the nominal DC-link voltage level for each IGBT in accordance with the voltage class of the IGBT. Today's conventional IGBT are basically available in $1.2 \mathrm{kV}$ and $1.7 \mathrm{kV}$ configurations up to currents 2400 [5]. From the high-voltage IGBTs the most widespread are $3.3 \mathrm{kV}$ as well as lately introduced $6.5 \mathrm{kV}$ IGBTs. Actually, connecting IGBTs in series allows fast high-power/high-voltage semiconductor switches with operating voltages of several kilovolts to be realized. Depending on the voltage blocking capability of the single transistors to be connected in series $(1.2 \mathrm{kV}, 1.7 \mathrm{kV}, 3.3 \mathrm{kV}$ or others), the total number of interconnected IGBTs to combine a high-voltage switch with the $6.5 \mathrm{kV}$ voltage blocking capability varies from 6 to 2. Such combined high-voltage switch can operate with the nominal DC-link voltage level of $3.6 \mathrm{kV}( \pm 20 \%)$. The $6.5 \mathrm{kV}$ IGBT modules recently implemented are basically designed for the operation with the DC-link voltages up to $4.2 \mathrm{kV}$. Such transistors give an attractive possibility to avoid series connection of IGBTs in case of $6.5 \mathrm{kV}$ switches thus achieving better efficiency, power density and reliability compared to the combined HV switch designs. Today's state-of-the-art $6.5 \mathrm{kV}$ IGBT modules are available in three basic configurations: with $200 \mathrm{~A}, 400 \mathrm{~A}$ and 600 A collector current capabilities. Table 1 provides an overview of operating voltages of different IGBT types and their minimal required number to combine a highvoltage switch with the $6.5 \mathrm{kV}$ voltage blocking capability.

Table (1). Evaluation of different candidate IGBTs for a high-voltage switch

\begin{tabular}{||c|c|c|c||}
\hline IGBT TYPE & $\begin{array}{c}\text { NOMINAL VALUE OF } \\
\mathbf{U}_{\text {DC }}, \mathbf{k V}( \pm \mathbf{2 0} \%)\end{array}$ & $\begin{array}{c}\text { MAX. BLOCKING } \\
\text { VOLTAGE } \\
\mathbf{U}_{\text {CEMAX }, \mathbf{~ k V}}\end{array}$ & $\begin{array}{c}\text { MIN. NUMBER OF } \\
\text { SERIES } \\
\text { CONNECTED FOR } \\
\mathbf{6 . 5} \mathbf{~ k V ~ S W I T C H}\end{array}$ \\
\hline $\mathbf{1 . 2}$ kV IGBT & 0.6 & 1.2 & 6 \\
\hline $1.7 \mathrm{kV}$ IGBT & 0.9 & 1.7 & 4 \\
\hline 3.3 kV IGBT & 1.8 & 3.3 & 2 \\
\hline 6.5 kV IGBT & 3.6 & 6.5 & 1 \\
\hline
\end{tabular}


As it seen from the Table 1, the series combination of lower voltage switches for the $6.5 \mathrm{kV}$ applications is connected to the even number $(2,4$ or 6$)$ of single IGBTs to be interconnected. Here, the most economical and technically feasible solution will be to implement the dual IGBT modules (half-bridges). The IGBT parameter mismatch in that case tend to be minimal (which is very important in the series connection) and space-weight constrains should be optimized with the reduced number of elements installed. The forthcoming analysis in this paper relies on the following IGBTs:

- Infineon $1.2 \mathrm{kV} / 200 \mathrm{~A}$ dual IGBT module BSM200GB120DLC,

- Infineon $1.7 \mathrm{kV} / 200 \mathrm{~A}$ dual IGBT module BSM200GB170DLC,

- Infineon $3.3 \mathrm{kV} / 200 \mathrm{~A}$ dual IGBT module FF200R33KF2C,

- Infineon 6.5 kV/200 A single IGBT module FZ200R65KF1.

Table 2 provides an overview of basic characteristic values of the investigated IGBTs.

Table (2): Characteristic values of different IGBTs analysed in the paper

\begin{tabular}{||l|c|c|c|c|c|c||}
\hline Type of IGBT & $\begin{array}{c}\text { Turn- } \\
\text { on } \\
\text { energy, } \\
\text { mJ }\end{array}$ & $\begin{array}{c}\text { Turn- } \\
\text { off } \\
\text { energy, } \\
\text { mJ }\end{array}$ & $\begin{array}{c}\text { FWD } \\
\text { reverse } \\
\text { recovery } \\
\text { energy, } \\
\text { mJ }\end{array}$ & $\begin{array}{c}\text { Collector- } \\
\text { emitter } \\
\text { saturation } \\
\text { voltage, V }\end{array}$ & $\begin{array}{c}\text { Overall } \\
\text { dimensions, } \\
\text { mm } \\
\text { (LxWxH) }\end{array}$ & $\begin{array}{c}\text { Weight } \\
\text { of a } \\
\text { module, } \\
\text { g }\end{array}$ \\
\hline $\begin{array}{l}\text { 1.2 kV IGBT } \\
\text { BSM200GB120 } \\
\text { DLC }\end{array}$ & 22 & 23 & 14 & 2.4 & $106 \times 61 \times 37$ & 340 \\
\hline $\begin{array}{l}\text { 1.7 kV IGBT } \\
\text { BSM200GB170 } \\
\text { DLC }\end{array}$ & 90 & 65 & 50 & 3.1 & $106 \times 61 \times 37$ & 420 \\
\hline $\begin{array}{l}\text { 3.3 kV IGBT } \\
\text { FZ200R33KF2C }\end{array}$ & 365 & 255 & 255 & 4.3 & $140 \times 73 \times 38$ & 500 \\
\hline $\begin{array}{l}\text { 6.5 kV IGBT } \\
\text { FZ200R65KF1 }\end{array}$ & 1900 & 1200 & 550 & 5.3 & $140 \times 73 \times 48$ & 500 \\
\hline
\end{tabular}

\section{Analysis of Technical and Economic Feasibility of Different HV Switch Solutions:}

Figure 1 (a) gives an overview of minimum installation surface area requirements for the different high-voltage switch solutions. The implementation of single high-voltage IGBTs (dual $3.3 \mathrm{kV}$ IGBT module or single $6.5 \mathrm{kV}$ IGBT) give a result of $30 \%$ and $90 \%$ reduced installation area requirements as compared to combined $\mathrm{HV}$ switches based on $1.7 \mathrm{kV}$ or $1.2 \mathrm{kV}$ IGBTs, respectively. Further, implementing dual $3.3 \mathrm{kV}$ IGBT or single $6.5 \mathrm{kV}$ IGBT the total weight of a combined $\mathrm{HV}$ switch could be reduced by $70 \%$ and $100 \%$, as compared to HV switch solutions with series connected $1.7 \mathrm{kV}$ and $1.2 \mathrm{kV}$ IGBT modules, respectively (Figure 1, b). 


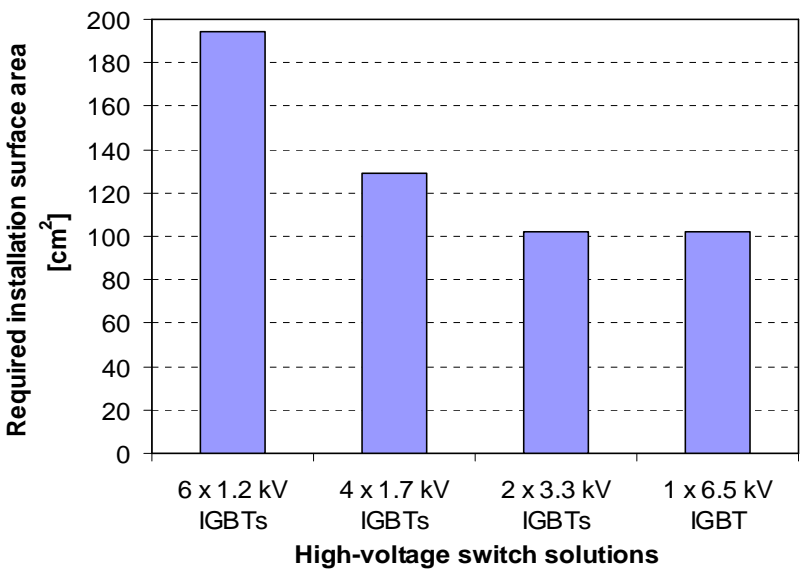

(a)

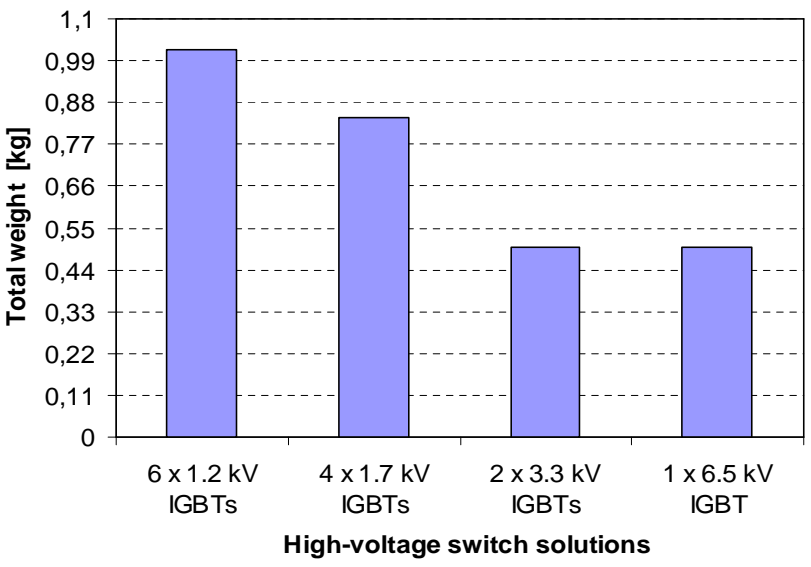

(b)

Figure (1): Comparison of installation surface area requirements (a) and total switch weight (b) for the different high-voltage switch solutions

Another essential aspect from the designer's point of view is the per switch price for the different high-voltage switch solutions. Figure 2 shows the price comparison chart for the different high-voltage switch solutions (IGBT drivers and auxiliary components are not considered). It must be noted here that due to its relative novelty and high manufacturing costs, the $6.5 \mathrm{kV}$ IGBT technology has low competibility than other HV switch solutions. For instance, the price for the single $6.5 \mathrm{kV} / 200$ A IGBT module is more than $50 \%$ and $40 \%$ higher as compared to $1.2 \mathrm{kV}$ and $3.3 \mathrm{kV}$ IGBT-based combined switch solution. Formally, the designer's "solution of choice" for the recent days is the series connection of $1.7 \mathrm{kV}$ IGBTs as more economical and technically feasible.

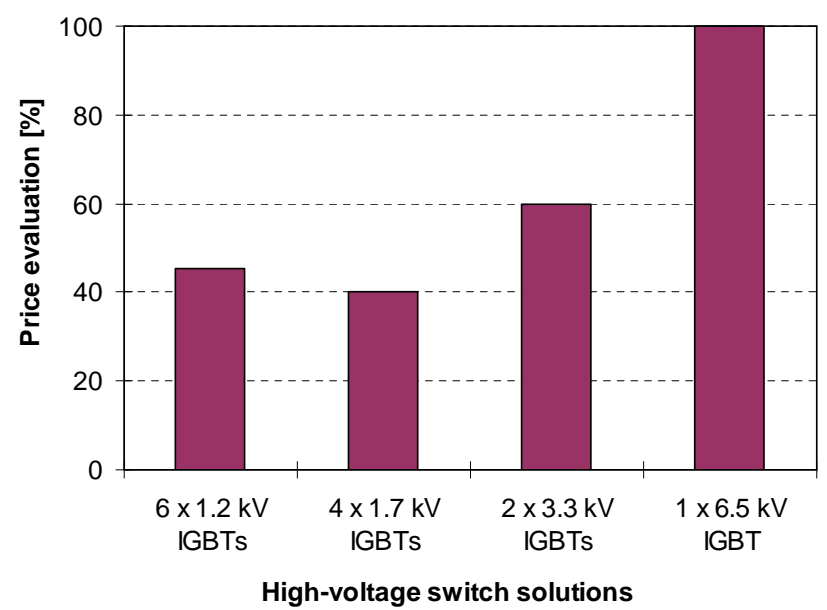

Figure (2): Price comparison for the different high-voltage switch solutions 3. Switching Performance Analysis of Different HV Switch Solutions:

Despite such advantages of power converters with the single $6.5 \mathrm{kV}$ IGBTs like simplicity and reliability, the overall design of them involves several limitations. They 
are mostly related to the specific properties of a single $6.5 \mathrm{kV}$ transistors and need to be taken into account during the development routine. The switching dynamics of IGBTs generally depends on such parameters as stray inductance and parasitic capacitance of the module as well as on the resistance of the gating circuit. The average per pulse turnon $\left(E_{\text {on }}\right)$ and turn-off $\left(E_{\text {off }}\right)$ energy losses for the different $6.5 \mathrm{kV} / 200$ A switch combinations as well as the freewheeling diode (FWD) reverse recovery energy in the hard-switching mode are compared in Figure $(3, \mathrm{a})$.

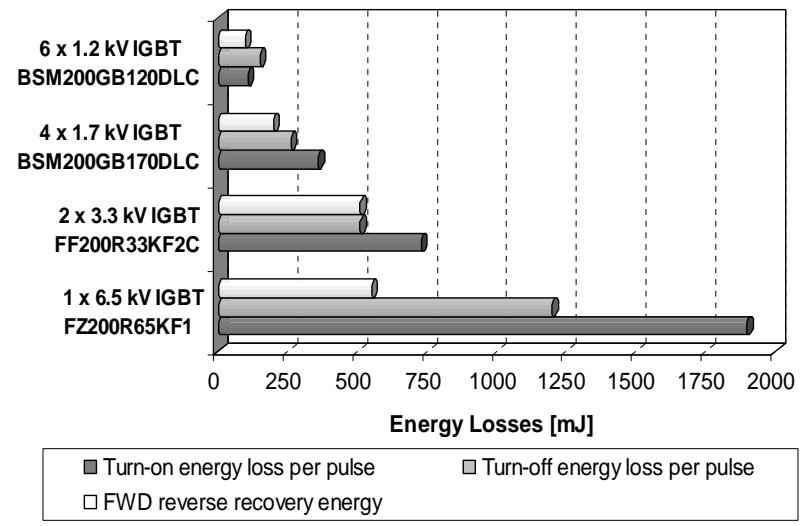

(a)

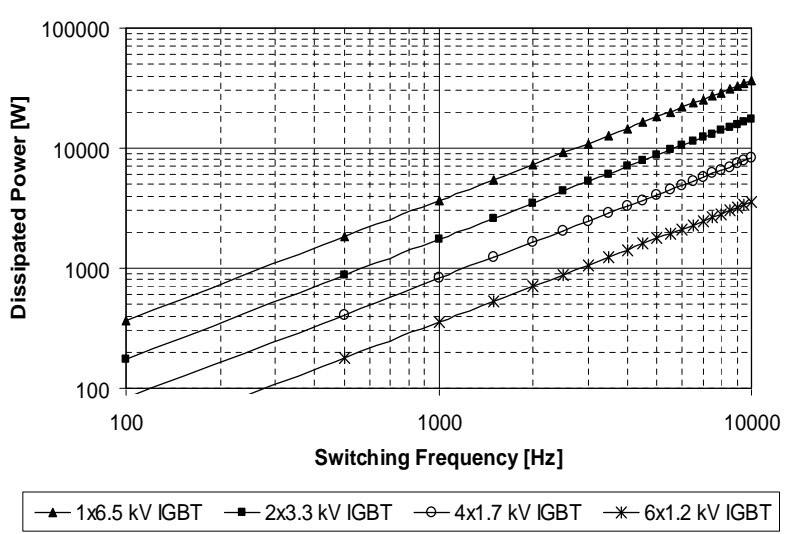

(b)

Figure (3): Average per pulse turn-on and turn-off energy losses and freewheeling diode recovery energy (a) and total dissipated power as a function of switching frequency (b) for the different $6.5 \mathrm{kV} / 200 \mathrm{~A}$ switch solutions

As it seen from Figure 3 (a), the switching energy losses and FWD reverse recovery energy of the $6.5 \mathrm{kV}$ IGBT are dramatically increased compared to the combined HV switch with series connected $1.2 \mathrm{kV}$ and $1.7 \mathrm{kV}$ IGBT and even to another representative of HV IGBT class - the $3.3 \mathrm{kV}$ IGBT. Thus, the series connected lowervoltage devices, mostly due to excellent thermal handling capability, have advantages in terms of switching losses, i.e. for the same amount of dissipated power the seriesconnected IGBTs could operate at higher switching frequencies (see Figure 3, b). In other words, operating with the same power the combined HV switch based on $3.3 \mathrm{kV}$, $1.7 \mathrm{kV}$ or $1.2 \mathrm{kV}$ IGBT gives a theoretical opportunity of 2,8 or even 20-times increased switching frequency in comparison with the single $6.5 \mathrm{kV}$ IGBT for the same dissipated power. It means, that the series connection could result in real improvements of converter weight and volume thanks to the possibility of operating with the higher switching frequencies.

\section{On-State Performance Analysis of Different HV Switch Solutions:}

Figure 4 (a) shows the collector-emitter voltage drop for different collector current values for the different high-voltage switch combinations. Due to the sum of voltage 
drops in series connection, as the number of series devices increase, the total collectoremitter voltage drop will also increase. This leads to dramatic increase in switch onstate losses: in 1.7 times in case of series-connected $3.3 \mathrm{kV}$ IGBTs or even in 2.5...2.7 times in case of series-connected $1.7 \mathrm{kV}$ or $1.2 \mathrm{kV}$ IGBTs as compared to single $6.5 \mathrm{kV}$ IGBT (see Figure 4, b).

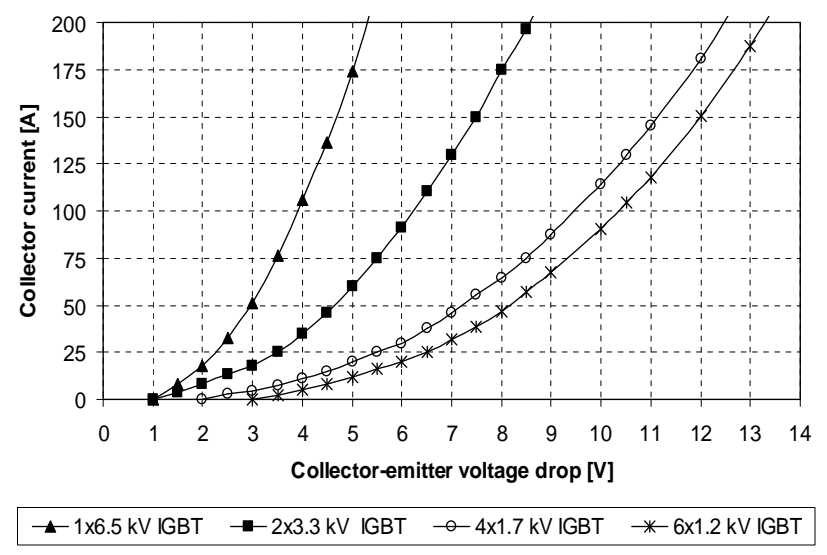

(a)

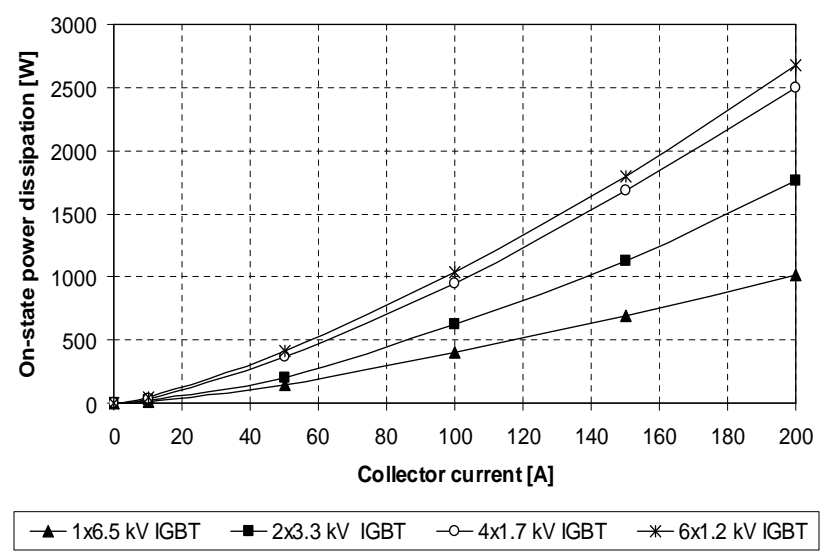

(b)

Figure (4): Collector-emitter voltage drop (a) and on-state power dissipation (b) for the different collector current values and different $6.5 \mathrm{kV} / 200 \mathrm{~A}$ switch solutions

\section{Total Power Dissipation and Loss Distribution of Different HV Switch Solutions:}

Basically, the operating frequency of the switched-mode power supply should be selected to obtain the best balance between switching losses, total transformer losses, size and cost of magnetic components and input/output capacitors. To conduct a detailed study of the different high-voltage switch solutions, simulations of switch losses in a two-level inverter arm were performed by the help of the Iposim software [8]. Simulation parameters were: modulation index $\mathrm{m}=1, \cos \varphi=0.9$, inverter arm rms current $\mathrm{I}_{\mathrm{Crms}}=200 \mathrm{~A}$. DC-link voltages were set in accordance with the IGBT class selected (see Table 1) and the power dissipated was finally multiplied by the number of series IGBTs. Only the hard switching mode was examined. All the maximum possible switching frequencies were selected upon the practical limits for the standard IGBTs for the hard switching:

- IGBT-modules, $1.2 \mathrm{kV}$ : $10 \mathrm{kHz}$;

- IGBT-modules, $1.7 \mathrm{kV}: 4 \mathrm{kHz}$;

- IGBT-modules, $3.3 \mathrm{kV}: 1.2 \mathrm{kHz}$;

- IGBT-modules, $6.5 \mathrm{kV}$ : $0.5 \mathrm{kHz}$.

Figure 5 gives an overview of static and dynamic loss distribition for IGBT and freewheeling diode (FWD) per inverter arm and for different HV switch solutions. Avoiding of series connection of lower voltage IGBTs by implementation of a single 
$6.5 \mathrm{kV}$ IGBT gives a strong effect of mimimization of total inverter losses mostly by means of reduced on-state (static) losses of IGBT and intergated freewheeling diode.
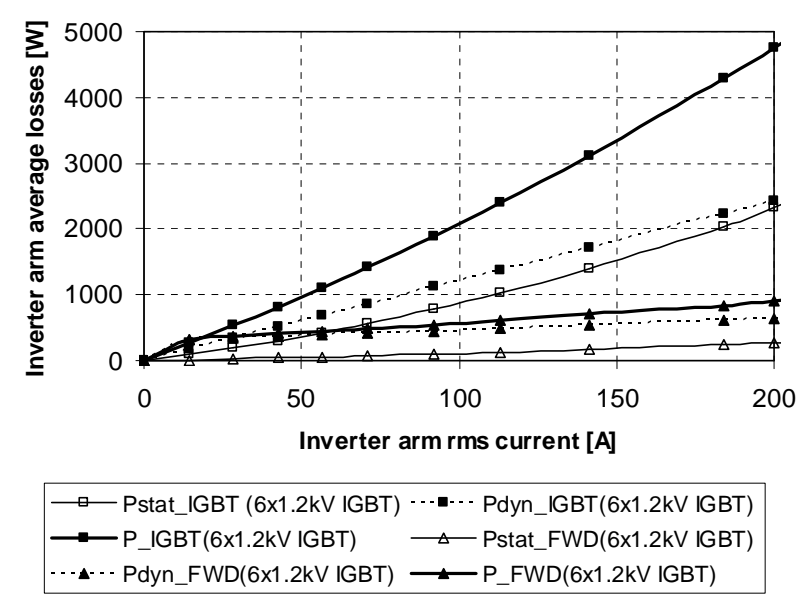

(a)
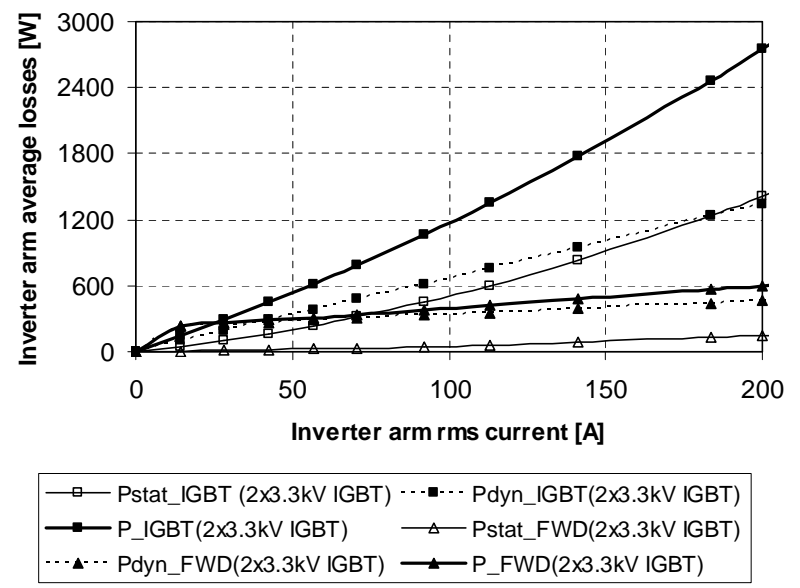

(c)
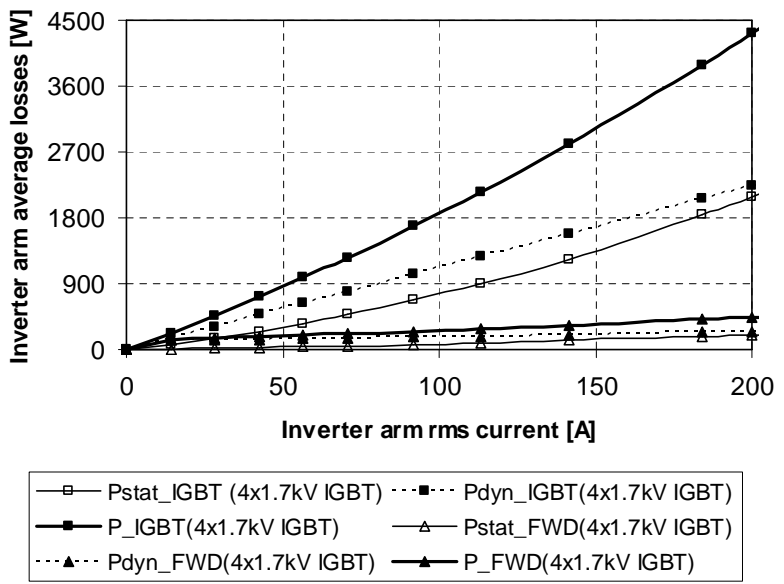

(b)
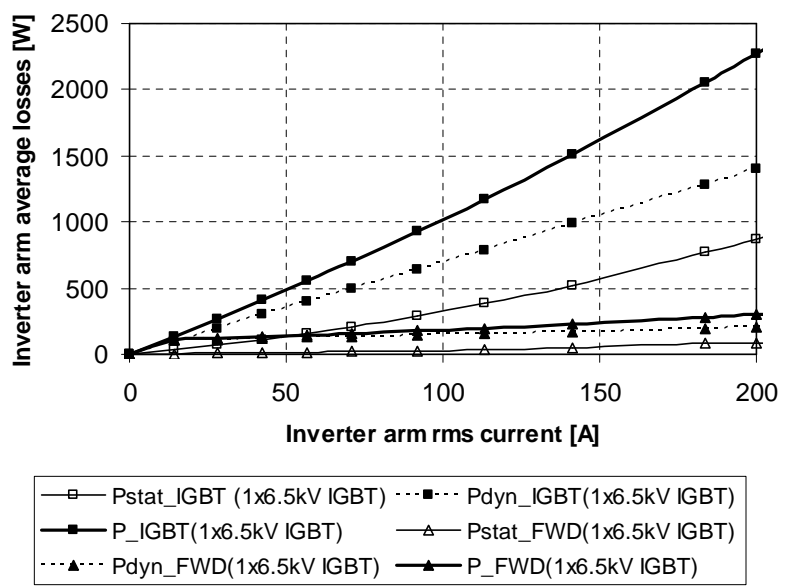

(d)

Figure (5): Distribition of on-state and dynamic losses for IGBT and freewheeling diode for the inverter arm with the different HV switch solutions: $6 x 1.2 \mathrm{kVIGBT}(a)$, $4 x 1.7 \mathrm{kV} \operatorname{IGBT}(b), 2 x 3.3 \mathrm{kVIGBT}(\mathrm{c})$ and $1 \times 6.5 \mathrm{kVIGBT}(\mathrm{d})$

Figure 6 (a) shows that the on-state and switching loss relations for the single $6.5 \mathrm{kV}$ IGBT and series connected $3.3 \mathrm{kV}, 1.7 \mathrm{kV}$ and $1.2 \mathrm{kV}$ IGBTs are $37 \%-63 \%, 46 \%-54 \%$, $48 \%-52 \%$, and $46 \%-54 \%$ at their upper switching frequency, respectively. It must be noted here that a proper tradeoff between the on-state voltage drop and the switching characteristics can be reached by the number and type of devices to be put in series. 


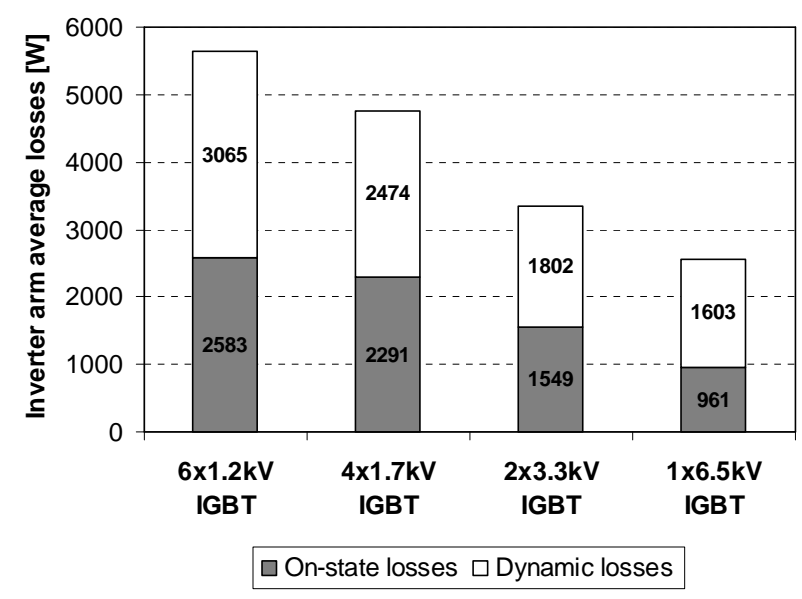

(a)

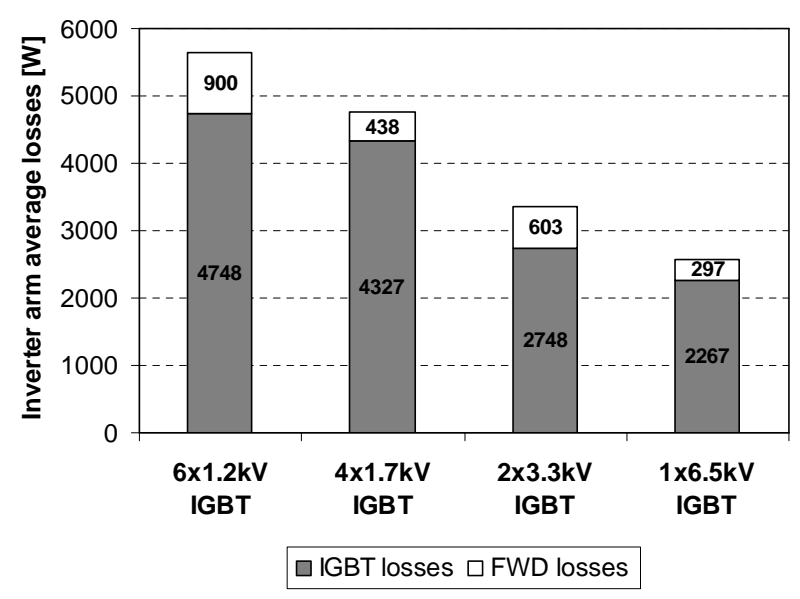

(b)

Figure (6): Inverter arm average losses breakdown for different HV switch solutions: on-state and dynamic loss distribution (a) and transistor and freewheeling diode loss distribution (b)

Due to better thermal handling capability of lower-voltage IGBTs, they can operate at sufficiently higher frequencies. However, the $200 \mathrm{~A} / 6.5 \mathrm{kV}$ switch based on series connected $1.2 \mathrm{kV}, 1.7 \mathrm{kV}$ or $3.3 \mathrm{kV}$ IGBTs is generating losses of $120 \%, 86 \%$ and, respectively, $31 \%$ higher than their single module high-voltage counterpart, thus required heatsinks with a proportionally higher efficiency. It is worth outlining that despite the total per switch loss level in all of these cases seems too high $(2.5 \ldots 4.5 \mathrm{~kW})$, they are less than $1 \%$ of the total switched power.

\section{Conclusions:}

This paper presents the feasibility study of the different IGBT switch solutions for the $6.5 \mathrm{kV} / 200 \mathrm{~A}$ application. The series connection of lower-voltage IGBTs as well as the implementation of a single high-voltage IGBT were compared in full load application with the switching frequencies selected upon the practical limits for the investigated types of IGBTs. It should be pointed out that the thermal limitation should be considered only for the IGBT transistors, whereas no thermal limitations exist with regard to the integrated freewheeling diodes for all of the modules investigated.

The selection between different HV switch solutions must be performed in accordance with the custom design requirements and must be precisely analyzed to achieve better price-weight-efficiency-reliability ratio. The performance analysis for the different HV switch solutions was done for the hard-switching mode. However, implementing softswitching the IGBT energy losses can be reduced significantly down to $8 \%$ (turn-on) or $30 \%$ (turn-off) of the hard-switching level [9]. 


\section{Acknowledgement:}

Authors thank Estonian Science Foundation (Grant No. 7425) for financial support of this study.

\section{References:}

[1] Abbate, C.; Busatto, G.; Fratelli, L.; Iannuzzo, F.; Cascone, B.; Giannini, G., Series connection of high power IGBT modules for traction applications, 2005 European Conference on Power Electronics and Applications, p. 8, 2005.

[2] Busatto, G.; Cascone, B.; Fratelli, L.; Luciano, A., Series connection of IGBTs in hardswitching applications, the 1998 IEEE Thirty-Third IAS Annual Meeting and Industry Applications Conference, vol. 2, pp.: 825 - 830, 1998.

[3] Castagno, S.; Curry, R.D.; Loree, E., Analysis and Comparison of a Fast Turn-On Series IGBT Stack and High-Voltage-Rated Commercial IGBTs, IEEE Transactions on Plasma Science, Volume 34, Issue 5, Part 1, Oct. 2006. Pp.:1692 - 1696.

[4] Gorgerino, A.; Guerra, A.; Kinzer, D.; Marcinkowski, J., Comparison of High Voltage Switches in Automotive DC-DC Converter, Power Conversion Conference PCC '07 Nagoya, pp.:360 - 367, 2007.

[5] Bernet, S., Recent developments of high power converters for industry and traction applications, IEEE Transactions on Power Electronics, Volume 15, Issue 6, November 2000, pp.:1102 - 1117.

[6] Gerster, C.; Hofer, P.; Karrer, N., Gate-control strategies for snubberless operation of series connected IGBTs, 27th Annual IEEE Power Electronics Specialists Conference, 1996. pp 1739 - 1742, vol. 2.

[7] Piazzesi, A.; Meysenc, L., Series connection of $3.3 \mathrm{kV}$ IGBTs with active voltage balancing, 35th Annual IEEE Power Electronics Specialists Conference, 2004. pp: 893 - 898, vol. 2.

[8] IPOSIM Simulation Tool for IGBT Modules, Infineon High Power Semiconductor (EUPEC), 2007.

[9] Schwarzer, U.; De Doncker, R.W., Characterization of $6.5 \mathrm{kV}$ IGBT modules for hardand soft-switching operation in medium voltage applications, in Proc. Twentieth Annual IEEE Applied Power Electronics Conference and Exposition, APEC 2005. pp.:329 - 335, vol. 1.

\section{Nomenclatures:}

$\mathrm{U}_{\text {b.c.,IGBT }}$... Input voltage blocking capability of a single IGBT

$\mathrm{n}$............. Number of series connected transistors

$\mathrm{U}_{\mathrm{DC}}$.......... Nominal value of the converter DC-link voltage

$\mathrm{E}_{\mathrm{on}}, \mathrm{E}_{\text {off }} \ldots$ Average per pulse turn-on and turn-off energy losses

$\mathrm{m}$............. Modulation index

$\mathrm{I}_{\mathrm{Crms}} \ldots \ldots . . . . \quad$ RMS current of inverter arm 